\title{
Effect of High-Intensity Focused Ultrasound on Eyebrow Lifting in Asians
}

\author{
Won Jong Oh, Hyun Jung Kwon, Sun Young Choi ${ }^{1}$, Kwang Ho Yoo ${ }^{2}$, Kui Young Park, Beom Joon Kim \\ Department of Dermatology, Chung-Ang University College of Medicine, ${ }^{1}$ Department of Dermatology, Inje University Seoul Paik \\ Hospital, Inje University College of Medicine, Seoul, ${ }^{2}$ Department of Dermatology, Catholic Kwandong University International St. Mary's \\ Hospital, Incheon, Korea
}

Dear Editor:

As skin aging progresses, the elasticity of the skin decreases and facial wrinkles are commonly seen. Various treatment modalities have been applied to treat wrinkles, yet patients are seeking more effective non-invasive methods with lower risk and minimal downtime. High-intensity focused ultrasound (HIFU) technology, originally used in cancer treatment to destroy cancer cells has emerged as an effective, non-surgical, tissue-tightening procedure ${ }^{1}$. There are several reported results for face, neck, and body tightening with the HIFU device. However, there are few clinical trials that objectively present the efficacy and safety of application of HIFU to the forehead in Asian people. A total of 30 Asian patients (25 females and 5 males) were enrolled in the study. Study approval was granted by the Chung-Ang University Hospital Institutional Review Boards (C2013149[1109]). We received the patient's consent form about publishing all photographic materials. All patients were treated with HIFU device (Ultraformer; Classys Inc., Seoul, Korea) with a 7-MHz, 3-mm transducer to the forehead. Local anesthetic was applied to the target region. Depending on the width of the forehead, the HIFU device was applied along 9 to 11 vertical lines (Fig. 1). Each line consisted of 10 shots at an interval of about $5 \mathrm{~mm}$. After

Received August 4, 2017, Revised February 1, 2018, Accepted for publication February 28, 2018

Corresponding author: Beom Joon Kim, Department of Dermatology, ChungAng University Hospital, 102 Heukseok-ro, Dongjak-gu, Seoul 06973, Korea. Tel: 82-2-6299-1525, Fax: 82-2-823-1049, E-mail: beomjoon@unitel.co.kr ORCID: https://orcid.org/0000-0003-2320-7621

This is an Open Access article distributed under the terms of the Creative Commons Attribution Non-Commercial License (http://creativecommons. org/licenses/by-nc/4.0) which permits unrestricted non-commercial use, distribution, and reproduction in any medium, provided the original work is properly cited.

Copyright (c) The Korean Dermatological Association and The Korean Society for Investigative Dermatology application of ultrasound transmission gel, the HIFU probe was accurately placed with equal pressure to connect to the skin surface. Ultrasound imaging functionality was used to check whether the probe acoustically connected to the skin tissue for treatment and whether the depth of focus was geometrically on the reticular dermis at an intermediate depth. For treatment, 90 110 shots of ultrasound exposure were applied along the lines, and irradiation was performed for 2 seconds or more per ultrasonic pulse. Ultrasonic exposure in the forehead region took about 5 to 10 minutes in total.

Before treatment, 4 weeks, and 12 weeks after treatment, standardized photographs of front and side views, rating scale values of pain, adverse events, physical findings, and patient satisfaction were recorded. We measured average eyebrow height $(\mathrm{AEH})$ and maximum eyebrow height

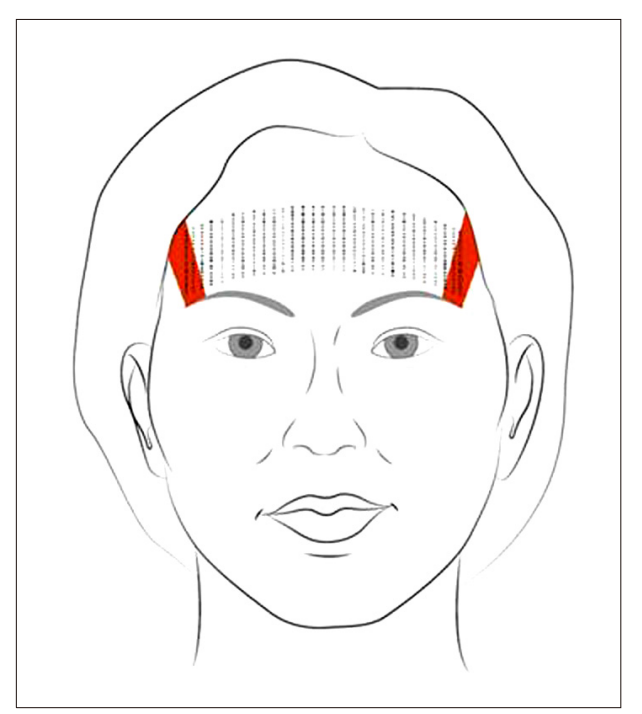

Fig. 1. Diagram showing proper distribution of line placement in the treatment region. Danger zones over the relative locations of the temporal branch of trigeminal nerves are highlighted in red. 

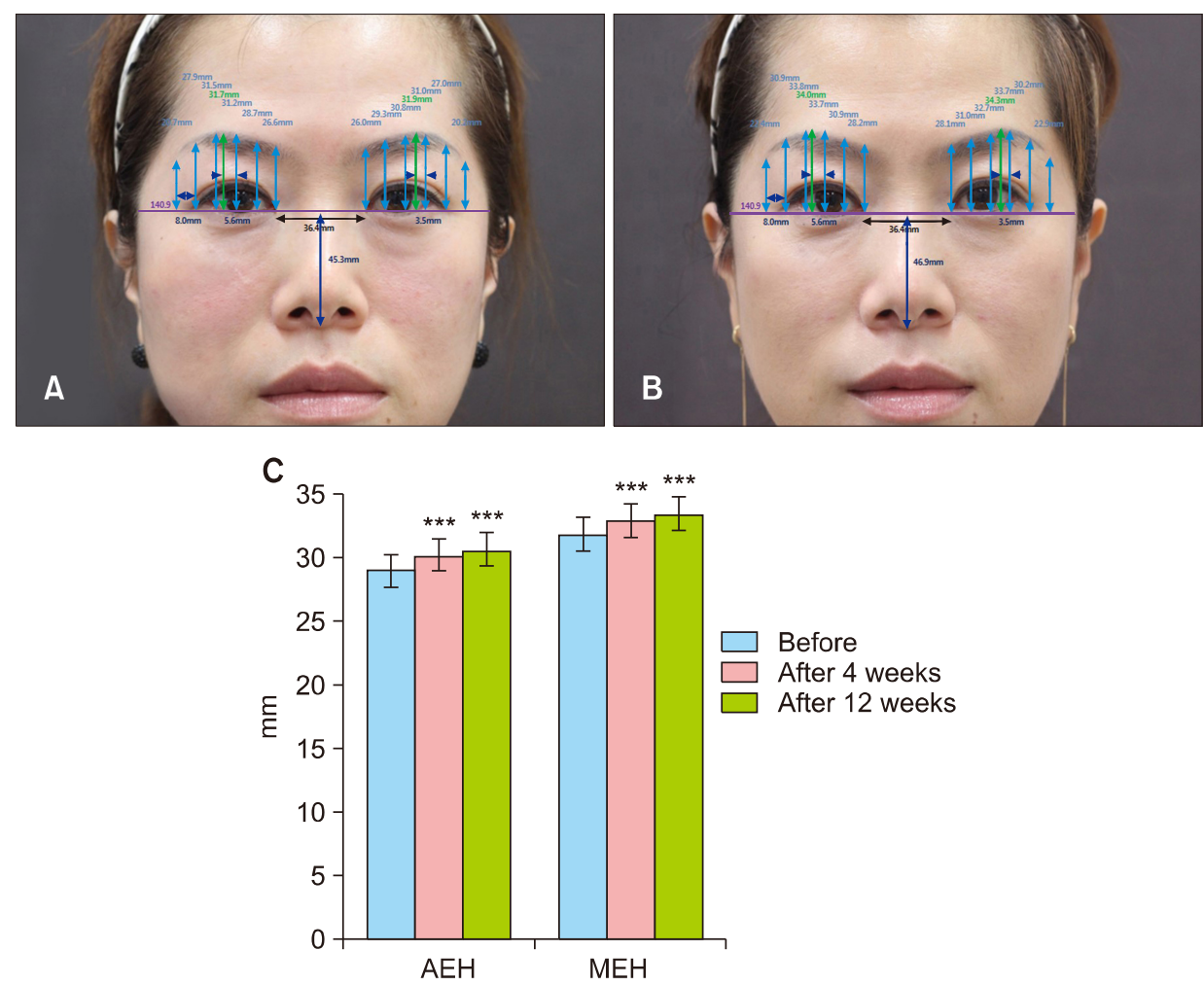

Fig. 2. Frontal view of a representative patient before (A) and 12 weeks after treatment (B). Note that superimposed lines and numbers are used to objectively measure brow position. Mean $\mathrm{AEH}$ and MEH (C) pre-treatment and 4 and 12 weeks post-treatment. AEH: average eyebrow height, $\mathrm{MEH}$ : maximum eyebrow height. $* * *$ Significant differences, $p<0.0001$ vs. before by paired $\mathrm{t}$-test.

(MEH) of the patients. Both medial canthi were connected on images of the facial region seen from the front. On the medial canthi connection line, five points were assigned incrementally at intervals of $8 \mathrm{~mm}$ from the inside of the eye and the distance to the top of the eyebrow from each point was measured. The calculated average of the measured values was taken as the $\mathrm{AEH}$, and the maximum distance from the medial canthi connection to the eyebrow was taken as the MEH (Fig. 2). Patients also rated their pain according to a visual analog scale (VAS). All adverse events, including local ones in the facial region, were included in a safety evaluation, and were recorded in the case report form and abnormalities were evaluated.

After application of the HIFU device, mean values of AEH and $\mathrm{MEH}$ significantly and progressively increased at 4 weeks and 12 weeks post-treatment compared with 0 weeks $(p<0.0001)$. Mean AEH immediately after treatment (visit 1), at week 4 (visit 2) and week 12 (visit 3) were 29.08 \pm 3.17 $\mathrm{mm}, 30.22 \pm 3.24 \mathrm{~mm}$ and $30.64 \pm 3.28 \mathrm{~mm}$, respectively. The difference in mean AEH from baseline was $1.14 \pm 0.29$ $\mathrm{mm}$ at week 4 (visit 2-visit 1 ) and $1.56 \pm 0.30 \mathrm{~mm}$ at week 12 (visit 3-visit 1); both changes were significant $(p<0.0001)$ (Fig. 2). Mean MEH immediately after treatment (visit 1), at week 4 (visit 2) and week 12 (visit 3) were 31.98 \pm 3.40 $\mathrm{mm}, 33.04 \pm 3.49 \mathrm{~mm}$ and $33.46 \pm 3.50 \mathrm{~mm}$, respectively. The difference in the mean MEH from baseline was $1.06 \pm 0.34 \mathrm{~mm}$ at week 4 (visit 2 -visit $1 ; p<0.0001$ ), and
$1.48 \pm 0.36 \mathrm{~mm}$ at week 12 (visit $3-$ visit1; $p<0.0001$ ) (Fig. 2). Immediately after treatment the mean VAS score for pain was $7.57 \pm 1.59$, but no pain was reported at weeks 4 and 12. No permanent adverse effects were observed during the follow-up period.

Skin tightening by delivery of nonablative energy offers the promise of reduction of wrinkles and sagging with minimal downtime and no serious adverse events ${ }^{2}$. Collagen is the primary protein in the dermis, together with subcutaneous fat septae and the superficial musculoaponeurotic system (SMAS). Ultrasound energy has specific characteristics that may increase its suitability for skin tightening. First, it is widely believed that energy delivery to the deeper subcutaneous layers of the face, or even the SMAS, is most effective in inducing skin tightening ${ }^{3}$. Furthermore, to the extent that this delivery can be divorced from secondary scatter and absorption in the epidermis and dermis, the risk of inadvertent cutaneous injury can be reduced. Besides ionizing radiation, ultrasound is the only type of inducible energy that can be delivered arbitrarily deeply into tissue in a selective manner ${ }^{4}$.

Quantification of improved skin elasticity after treatment in a purely objective manner would be of great benefit for skin tightening procedures. As there is a limitation in scientific objectivity for subjective visual assessment from photographic documentation, eyebrow height was assessed using a standard measurement technique ${ }^{5,6}$. In this 
study, to ensure uniform assessment of change in eyebrow elevation, we used $\mathrm{AEH}$ and $\mathrm{MEH}$.

Several studies have reported that HIFU resulted in an improvement of facial laxity. Alam et al. ${ }^{2}$ have reported that a single ultrasound treatment of the forehead produced average brow height elevation of 1.7 to $1.9 \mathrm{~mm}$. Suh et al. ${ }^{4}$ have showed that $61.5 \%$ of eyebrows were lifted by at least $0.5 \mathrm{~mm}$ at 6 months. Compared with results of the above studies, our study demonstrated significant improvement of forehead skin laxity. In conclusion, we suggest that HIFU would be useful for lax eyelid conditions such as ptosis, as it had a positive effect on eyebrow lifting in Asian people. Future studies could use intense ultrasound probes focused deeper into the tissue to achieve greater tightening efficacy. Higher resolution diagnostic ultrasound imaging would provide better intraoperative visualization of the facial tissue layers, thus facilitating precise treatment and giving better results for skin laxity. Further studies are planned in the field of skin tightening, wrinkle improvement, and skin lifting on other sites of the face.

\section{CONFLICTS OF INTEREST}

The authors have nothing to disclose.

\section{ORCID}

Won Jong Oh, https://orcid.org/0000-0001-5201-7849

Hyun Jung Kwon, https://orcid.org/0000-0001-8376-2358

Sun Young Choi, https://orcid.org/0000-0003-0248-7708
Kwang Ho Yoo, https://orcid.org/0000-0002-0137-6849

Kui Young Park, https://orcid.org/0000-0001-5965-1754

Beom Joon Kim, https://orcid.org/0000-0003-2320-7621

\section{REFERENCES}

1. Laubach HJ, Makin IR, Barthe PG, Slayton MH, Manstein D. Intense focused ultrasound: evaluation of a new treatment modality for precise microcoagulation within the skin. Dermatol Surg 2008;34:727-734.

2. Alam M, White LE, Martin N, Witherspoon J, Yoo S, West DP. Ultrasound tightening of facial and neck skin: a raterblinded prospective cohort study. J Am Acad Dermatol 2010;62:262-269.

3. Har-Shai Y, Bodner SR, Egozy-Golan D, Lindenbaum ES, Ben-Izhak O, Mitz $\mathrm{V}$, et al. Mechanical properties and microstructure of the superficial musculoaponeurotic system. Plast Reconstr Surg 1996;98:59-70; discussion 71-73.

4. Suh DH, Oh YJ, Lee SJ, Rho JH, Song KY, Kim NI, et al. A intense-focused ultrasound tightening for the treatment of infraorbital laxity. J Cosmet Laser Ther 2012;14:290-295.

5. Fitzpatrick R, Geronemus R, Goldberg D, Kaminer $M$, Kilmer S, Ruiz-Esparza J. Multicenter study of noninvasive radiofrequency for periorbital tissue tightening. Lasers Surg Med 2003;33:232-242.

6. Nahm WK, Su TT, Rotunda AM, Moy RL. Objective changes in brow position, superior palpebral crease, peak angle of the eyebrow, and jowl surface area after volumetric radiofrequency treatments to half of the face. Dermatol Surg 2004;30:922-928; discussion 928. 